\title{
The profile of the Greek 'XXL' family
}

\author{
Athanasios Christoforidis ${ }^{1, *}$, Spyros Batzios ${ }^{1}$, Haralampos Sidiropoulos ${ }^{2}$, Maria \\ Provatidou $^{2}$ and Dimitris Cassimos ${ }^{3}$ \\ ${ }^{1} 1$ st Paediatric Department, Aristotle University, Thessaloniki, 49, Konstantinoupoleos Street, \\ 54246 Thessaloniki, Greece: ${ }^{2}$ Health Centre of Eleftheroupoli, Kavala, Greece: ${ }^{3}$ Paediatric Department, \\ Dimokritio University, Alexandroupoli, Greece
}

Submitted 22 November 2010: Accepted 22 March 2011: First published online 16 May 2011

\begin{abstract}
Objective: To identify Greek families in which all members were overweight or obese (XXL families) and to describe their profile with regard to their socioeconomic status and their eating behaviours and practices.

Design: A prospective cohort study.

Setting: The metropolitan area of Kavala.

Subjects: We recruited children aged 11 and 12 years from twelve primary schools, and their parents, from volunteers. Auxologic measurements of the children included height and weight. A structured questionnaire pertaining to information on the socio-economic status of the family, anthropometric values and educational status of parents, dietary habits and the availability of various food products and beverages at home, as well as dietary intake, physical activity, time spent sleeping and time spent watching television, was filled in by one of the parents of each child. A total of 331 families finally participated.

Results: In sixty-one families (18.43\%) both parents and child were either overweight or obese (XXL family), and in seven of these families all members were obese. Only twenty-eight families $(8 \cdot 46 \%)$ had all members with a normal BMI. The XXL family was associated with lower educational status of both parents, whereas a higher percentage of XXL families resided in rural areas and had lower income. Skipping breakfast and spending more than $3 \mathrm{~h}$ in front of a screen every day were more frequently observed in XXL families. With regard to the availability of various food products and beverages at home, no significant differences were observed between XXL families and the rest of the studied families.

Conclusions: Greek XXL families have lower educational status and lower annual income.
\end{abstract}

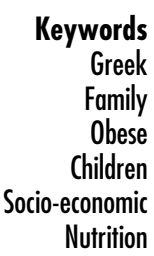

Childhood obesity has reached epidemic proportions in most industrialized countries and in several low-income countries, especially in urban areas ${ }^{(1)}$. Currently, Greece has one of the highest rates of paediatric obesity worldwide ${ }^{(2)}$, with an alarmingly increasing trend observed between 1997 and 2004, which has apparently been levelling-off since the last half of the decade ${ }^{(3)}$. Obese and overweight children are more likely to exhibit components of the metabolic syndrome, such as increased blood pressure and abnormal glucose and lipid metabolism ${ }^{(4)}$. In addition, childhood obesity in most cases tracks into adulthood and thereby has lasting adverse health effects ${ }^{(5,6)}$.

Parental obesity plays an important role in predicting children's risk of obesity in adulthood. It is estimated that a family history of obesity more that doubles the risk of adult obesity among both obese and non-obese children under the age of 10 years ${ }^{(5)}$. Parental, especially maternal, obesity has also been identified as a significant predictor of obesity in the offspring during childhood ${ }^{(7)}$. Family members share both genes and environmental factors. More than 600 genes, markers and chromosomal regions have been currently identified to be involved in body weight regulation and obesity development according to the latest version of the Gene Obesity Map ${ }^{(8)}$. However, this gene effect seems to account for as much as $40 \%$ of the variation in BMI or fat mass ${ }^{(9)}$. Environmental influences including parental modelling of eating behaviours, food choices, child feeding practices and socio-economic factors seem to play an important role in the development of obesity in every family member. However, these environmental factors have not been exclusively studied in families in which all members are overweight and/or obese.

The objective of the present study was to identify Greek families in which all members were overweight or obese (XXL families) and to describe their profile with regard to their socio-economic status and their eating 
behaviours and practices, further aiming to determine the best approaches for preventing interventions.

\section{Subjects and methods}

We recruited children aged 11 and 12 years and their parents from volunteers between September 2008 and May 2009. All participants resided in the Kavala metropolitan area and were recruited from twelve primary schools that were randomly selected and located in both urban and rural regions within the prefecture of Kavala, northern Greece. The sole inclusion criterion was enrolment in the fifth or sixth grade of a primary school; there were no exclusion criteria. A letter explaining the aim of the study was provided to each parent and an informative speech was made on the day before the measurements were to be taken. Written informed consent, in accordance with the revised version of the Helsinki Declaration regarding research involving human subjects, was obtained from all parents or legal guardians. The study was approved by the Ministry of National Education and Religious Affairs, by Kavala's public school supervisor and by the head principal and teachers of the schools included.

Auxologic measurements of the children were obtained in the school setting with the participants wearing light clothing and no shoes. Height was measured using a regularly calibrated, wall-mounted ruler (Minimetre; Raven Equipment Limited, Dunmow, UK) and expressed in centimetres rounded to the nearest $0.5 \mathrm{~cm}$. Weight was measured on a portable electronic scale (model 901; Seca, Hamburg, Germany) and expressed in kilograms to the nearest $0.5 \mathrm{~kg}$. BMI was calculated as weight in kilograms divided by the square of height in metres $\left(\mathrm{kg} / \mathrm{m}^{2}\right.$, Quetelet index). Overweight and obesity were determined according to the International Obesity Task Force (IOTF) standards for age and sex developed by Cole et $a{ }^{(10)}$. For adults, overweight was identified as BMI $\geq 25 \cdot 0 \mathrm{~kg} / \mathrm{m}^{2}$ and obesity as BMI $\geq 30 \cdot 0 \mathrm{~kg} / \mathrm{m}^{2}$, according to standard definitions laid down by $\mathrm{WHO}^{(11)}$.

A structured questionnaire consisting of twenty-one multiple choice or open-ended questions was filled in by one of the parents of each child at home. The aim of the questionnaire was to collect information on the socioeconomic status of the family, as well as anthropometric values (weight and height) and the educational status of parents, their diet history, dietary habits, the availability of various food products and beverages at home, dietary intake, physical activity, time spent sleeping and time spent watching television.

For statistical analysis the SPSS for Windows statistical software package version $17 \cdot 0$ (SPSS Inc., Chicago, IL, USA) was used. Percentages were compared using the $\chi^{2}$ test, whereas means were compared using the unpaired Student $t$ test. A $P$ value $<0 \cdot 05$ was considered statistically significant. Finally, logistic regression models (univariate and multivariate, stepwise) were used for the identification of parameters that predict an XXL family.

\section{Results}

A total of 331 families returned completed questionnaires and were included in the final statistical analysis. In sixtyone families (18.43\%) both parents and child were overweight or obese, and in seven of these families all members were obese. From the 270 families (81.57\%) in which not all members were overweight or obese, more than half ( $n$ 140) had two members classified as overweight or obese, whereas an additional 102 families had one member who was overweight or obese. Only twenty-eight families ( $8.46 \%$ of the total number of studied families) had normal BMI in all members. A total of 165 fathers were overweight (48.04\%) and eighty-three (25.08\%) were obese. The corresponding figures for mothers were $100(43 \cdot 20 \%)$ and forty-four $(13 \cdot 29 \%)$, respectively, for overweight and obesity. Overall, overweight was identified in 111 children $(33 \cdot 80 \%)$, whereas obesity was identified in fifty-one (15.40\%). A schematic demonstration of the distribution of overweight and obesity among members of the studied families is presented in Fig. 1.

When families were classified on the basis of all members being overweight or obese (XXL family) or having at least one member with normal weight, two groups consisting of sixty-one (18.43\%) and 270 $(81.57 \%)$ families were formed (Groups A and B; Fig. 1). The XXL family (Group A) was characterized by a lower educational status of both parents, as a significantly increased percentage of fathers and mothers had only primary-school education compared with parents in Group B $(34.42 \% v$. 18.89\%, $P<0.005$ and $29.51 \% v$. $17 \cdot 78 \%, P<0 \cdot 03$, respectively; Table 1$)$. In addition, the XXL family was inversely associated with maternal tertiary education as only $8 \cdot 20 \%$ compared with $30 \cdot 37 \%$ $(P=0 \cdot 0006)$ of mothers in XXL families attained a higher educational level. Although the XXL family seemed to reside more in rural areas than in cities and to have a lower income, these differences did not reach statistical significance. On the other hand, skipping breakfast and spending more than $3 \mathrm{~h}$ in front of a screen (mainly television watching) per day were more frequently observed in XXL families (Table 1).

With regard to the availability of various food products and beverages at home, no significant differences were observed between XXL families and the rest of the studied families (Table 2). However, when the XXL families were compared with twenty-eight families in which all members had normal BMI (Group C; Fig. 1), significantly increased availability of sweets and juices was recorded in the XXL families (Table 3). Finally, weekly consumption of fish, vegetables, fruit and, surprisingly, pasta was significantly higher in normal families compared with XXL 


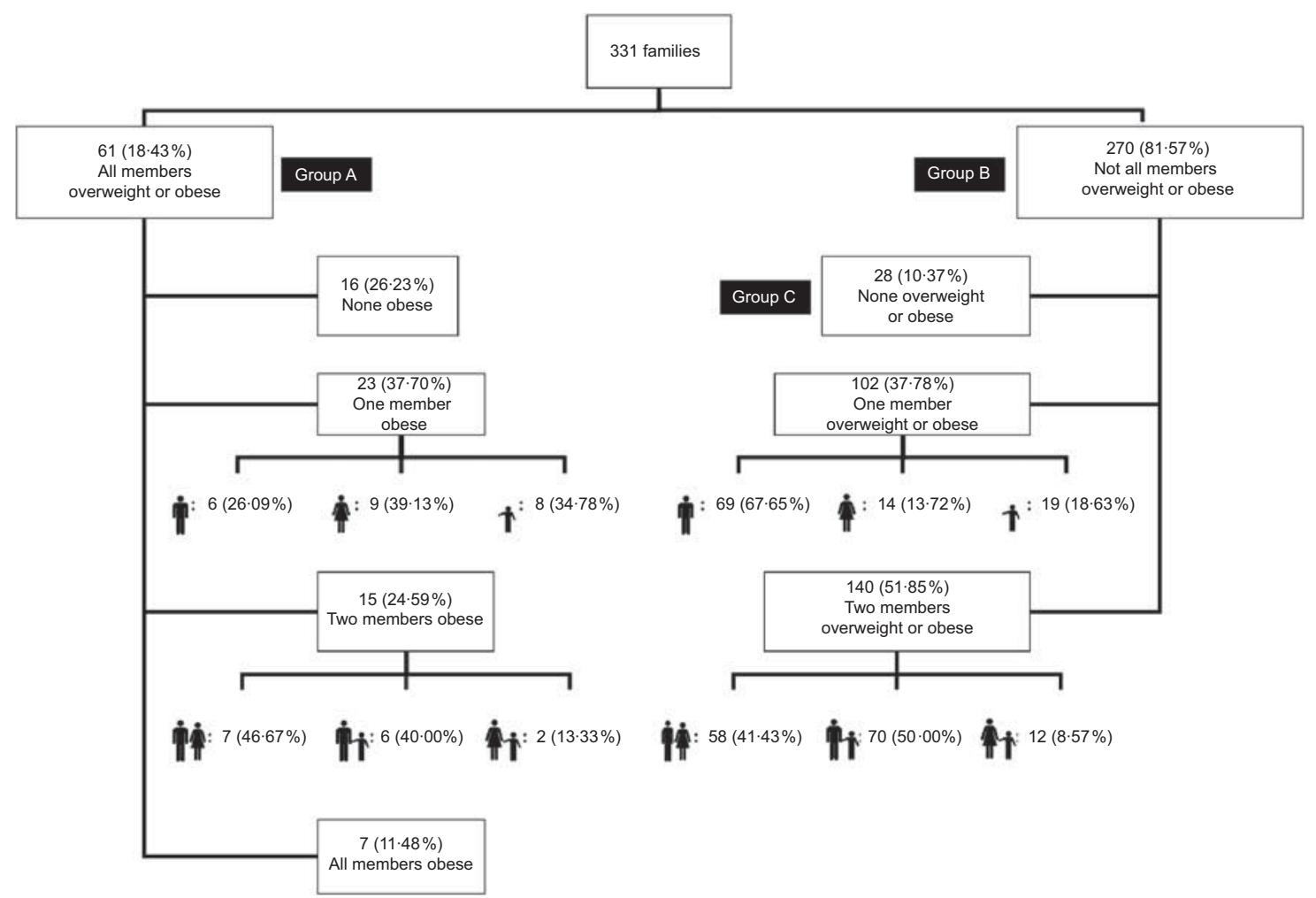

Fig. 1 Distribution of overweight and obesity among members of the studied families

Table $1 \mathrm{~A}$ comparison of socio-economic and demographic characteristics, as well as eating and television-viewing habits, between families in which all members are overweight or obese (XXL families) and other families

\begin{tabular}{|c|c|c|c|c|c|}
\hline \multirow[b]{2}{*}{ Parameters } & \multicolumn{2}{|c|}{$\begin{array}{l}\text { All members are overweight } \\
\text { or obese }(n 61,18 \cdot 43 \%)\end{array}$} & \multicolumn{2}{|c|}{$\begin{array}{l}\text { Not all members are overweight } \\
\text { or obese }(n 270,81.57 \%)\end{array}$} & \multirow[b]{2}{*}{$P$} \\
\hline & $n$ & $\%$ & $n$ & $\%$ & \\
\hline \multicolumn{6}{|l|}{ Father's educational status } \\
\hline Primary school & 21 & $34 \cdot 42$ & 51 & $18 \cdot 89$ & $0.005^{\star}$ \\
\hline Tertiary education & 9 & $14 \cdot 75$ & 73 & $27 \cdot 04$ & 0.06 \\
\hline \multicolumn{6}{|l|}{ Mother's educational status } \\
\hline Primary school & 18 & $29 \cdot 51$ & 48 & $17 \cdot 78$ & $0.03^{*}$ \\
\hline Tertiary education & 5 & $8 \cdot 20$ & 82 & $30 \cdot 37$ & $0.0006^{*}$ \\
\hline \multicolumn{6}{|l|}{ Annual income $(€)$} \\
\hline$<10000$ & 20 & $32 \cdot 79$ & 76 & $28 \cdot 15$ & 0.37 \\
\hline$>20000$ & 16 & $26 \cdot 23$ & 92 & $34 \cdot 07$ & $0 \cdot 31$ \\
\hline Single-parent family & 3 & 4.92 & 15 & $5 \cdot 56$ & $0 \cdot 89$ \\
\hline Single-child family & 11 & 18.03 & 80 & $29 \cdot 63$ & 0.09 \\
\hline \multicolumn{6}{|l|}{ Residence } \\
\hline Rural & 16 & $26 \cdot 23$ & 59 & $21 \cdot 85$ & 0.37 \\
\hline City & 10 & $16 \cdot 39$ & 75 & $27 \cdot 78$ & 0.09 \\
\hline \multicolumn{6}{|l|}{ Meal duration (min) } \\
\hline Mean & \multirow{3}{*}{\multicolumn{2}{|c|}{$\begin{array}{c}17 \cdot 13 \\
7 \cdot 23 \\
5 \cdot 00-30 \cdot 00\end{array}$}} & \multirow{3}{*}{\multicolumn{2}{|c|}{$\begin{array}{c}19.96 \\
9 \cdot 37 \\
4 \cdot 00-60 \cdot 00\end{array}$}} & $0.012^{*}$ \\
\hline SD & & & & & \\
\hline Range & & & & & \\
\hline Three or fewer meals per day & 20 & $32 \cdot 79$ & 60 & $22 \cdot 22$ & 0.06 \\
\hline No breakfast & 16 & $26 \cdot 23$ & 28 & $10 \cdot 37$ & $0.0006^{*}$ \\
\hline Not eating in the kitchen or in the dining room & 6 & $9 \cdot 84$ & 14 & $5 \cdot 19$ & $0 \cdot 14$ \\
\hline Child eating alone & 5 & $8 \cdot 20$ & 15 & $5 \cdot 56$ & 0.39 \\
\hline Watching television while eating & 27 & $44 \cdot 26$ & 117 & $43 \cdot 33$ & $0 \cdot 72$ \\
\hline Screen time $(>3 \mathrm{~h} / \mathrm{d})$ & 11 & 18.03 & 25 & $9 \cdot 26$ & $0.04^{*}$ \\
\hline
\end{tabular}

*Statistically significant difference $(P \leq 0.05)$.

families. In contrast, XXL families were more frequently consuming products that were not homemade (mainly pizza and meat products).
Table 4 shows only parameters with statistically significant odds for predicting XXL families in the univariate analysis. When these statistically significant variables 
Table 2 A comparison of home availability of various food products or beverages and weekly food consumption between XXL families and other families

\begin{tabular}{|c|c|c|c|c|c|}
\hline \multirow[b]{2}{*}{ Parameters } & \multicolumn{2}{|c|}{$\begin{array}{l}\text { All members are overweight } \\
\text { or obese }(n 61)\end{array}$} & \multicolumn{2}{|c|}{$\begin{array}{l}\text { Not all members are overweight } \\
\text { or obese }(n 270)\end{array}$} & \multirow[b]{2}{*}{$P$} \\
\hline & $n$ & $\%$ & $n$ & $\%$ & \\
\hline \multicolumn{6}{|l|}{ Always in-house } \\
\hline Sweets & 28 & $45 \cdot 90$ & 147 & $54 \cdot 44$ & 0.34 \\
\hline Soft drinks & 20 & $32 \cdot 79$ & 92 & $34 \cdot 07$ & 0.99 \\
\hline Juice & 44 & $72 \cdot 13$ & 227 & $84 \cdot 07$ & $0 \cdot 10$ \\
\hline Nuts & 19 & $31 \cdot 15$ & 114 & $42 \cdot 22$ & $0 \cdot 16$ \\
\hline Chips & 14 & $22 \cdot 95$ & 59 & $21 \cdot 85$ & 0.74 \\
\hline \multicolumn{6}{|l|}{ Never in-house } \\
\hline Sweets & 21 & $34 \cdot 42$ & 74 & $27 \cdot 41$ & $0 \cdot 20$ \\
\hline Soft drinks & 26 & $42 \cdot 62$ & 140 & $51 \cdot 85$ & 0.29 \\
\hline Juice & 11 & $18 \cdot 03$ & 35 & $12 \cdot 96$ & 0.25 \\
\hline Nuts & 35 & $57 \cdot 38$ & 153 & $56 \cdot 67$ & 0.69 \\
\hline Chips & 41 & $67 \cdot 21$ & 196 & $72 \cdot 59$ & 0.66 \\
\hline \multicolumn{6}{|c|}{ Food group ( $\geq 4$ times/week) } \\
\hline Pasta & 9 & $14 \cdot 75$ & 45 & $16 \cdot 67$ & 0.80 \\
\hline Rice & 2 & $3 \cdot 28$ & 21 & $7 \cdot 78$ & 0.23 \\
\hline Fish & 0 & 0.00 & 20 & $7 \cdot 41$ & $0.03^{*}$ \\
\hline Meat & 25 & $40 \cdot 98$ & 106 & $39 \cdot 26$ & 0.64 \\
\hline Legumes & 2 & $3 \cdot 28$ & 29 & $10 \cdot 74$ & 0.08 \\
\hline Vegetables & 20 & $32 \cdot 79$ & 128 & $47 \cdot 41$ & 0.06 \\
\hline Salads & 43 & $70 \cdot 49$ & 189 & $70 \cdot 00$ & 0.63 \\
\hline Fruit & 42 & $68 \cdot 85$ & 189 & $70 \cdot 00$ & 0.83 \\
\hline Not homemade & 21 & $34 \cdot 42$ & 75 & $27 \cdot 78$ & 0.22 \\
\hline
\end{tabular}

${ }^{*}$ Statistically significant difference $(P \leq 0.05)$.

Table 3 A comparison of home availability of various food products or beverages and weekly food consumption between families in which all members are overweight or obese and families in which all members have normal weight

\begin{tabular}{|c|c|c|c|c|c|}
\hline \multirow[b]{2}{*}{ Parameters } & \multicolumn{2}{|c|}{$\begin{array}{c}\text { All members are overweight } \\
\text { or obese }(n 61)\end{array}$} & \multicolumn{2}{|c|}{$\begin{array}{l}\text { All members are } \\
\text { normal }(n 28)\end{array}$} & \multirow[b]{2}{*}{$P$} \\
\hline & $n$ & $\%$ & $n$ & $\%$ & \\
\hline \multicolumn{6}{|l|}{ Always in-house } \\
\hline Sweets & 28 & $45 \cdot 90$ & 4 & $14 \cdot 29$ & $0.004^{*}$ \\
\hline Beverages & 20 & $32 \cdot 79$ & 6 & $21 \cdot 42$ & 0.27 \\
\hline Juice & 44 & $72 \cdot 13$ & 14 & $50 \cdot 00$ & $0.04^{*}$ \\
\hline Nuts & 19 & $31 \cdot 15$ & 4 & $14 \cdot 29$ & 0.09 \\
\hline Chips & 14 & $22 \cdot 95$ & 2 & $7 \cdot 14$ & 0.07 \\
\hline \multicolumn{6}{|l|}{ Never in-house } \\
\hline Sweets & 21 & $34 \cdot 42$ & 12 & $42 \cdot 86$ & 0.44 \\
\hline Beverages & 26 & $42 \cdot 62$ & 13 & $46 \cdot 63$ & 0.74 \\
\hline Juice & 11 & $18 \cdot 03$ & 0 & 0.00 & $0 \cdot 016^{\star}$ \\
\hline Nuts & 35 & $57 \cdot 38$ & 14 & $50 \cdot 00$ & 0.52 \\
\hline Chips & 41 & $67 \cdot 21$ & 17 & $60 \cdot 71$ & 0.55 \\
\hline \multicolumn{6}{|c|}{ Food group ( $\geq 4$ times/week) } \\
\hline Pasta & 9 & $14 \cdot 75$ & 10 & $35 \cdot 71$ & $0.025^{\star}$ \\
\hline Rice & 2 & $3 \cdot 28$ & 4 & $14 \cdot 29$ & 0.054 \\
\hline Fish & $\overline{0}$ & 0.00 & 2 & $7 \cdot 14$ & $0.034^{*}$ \\
\hline Meat & 25 & $40 \cdot 98$ & 14 & $50 \cdot 00$ & 0.43 \\
\hline Legumes & 2 & $3 \cdot 28$ & 4 & $14 \cdot 29$ & 0.054 \\
\hline Vegetables & 20 & $32 \cdot 79$ & 17 & $60 \cdot 71$ & $0.013^{*}$ \\
\hline Salads & 43 & $70 \cdot 49$ & 24 & $85 \cdot 71$ & $0 \cdot 12$ \\
\hline Fruit & 42 & $68 \cdot 85$ & 26 & $92 \cdot 86$ & $0.013^{*}$ \\
\hline Not homemade & 21 & $34 \cdot 42$ & 2 & $7 \cdot 14$ & $0.006^{\star}$ \\
\hline
\end{tabular}

*Statistically significant difference $(P \leq 0.05)$.

were introduced in a multivariate model, screen time for $>3 \mathrm{~h} / \mathrm{d}$ and reduced meal duration were found to be independent risk factors for overweight or obesity among all members of the family.

\section{Discussion}

Several studies provide compelling evidence of genetic influence on obesity, with some of the strongest support 
Table 4 Logistic regression models (univariate and multivariate, stepwise) for predicting an XXL family

\begin{tabular}{|c|c|c|c|c|c|c|}
\hline \multirow[b]{2}{*}{ Parameters } & \multicolumn{3}{|c|}{ Univariate } & \multicolumn{3}{|c|}{ Multivariate } \\
\hline & OR & $95 \% \mathrm{Cl}$ & $P$ & OR & $95 \% \mathrm{Cl}$ & $P$ \\
\hline Meal duration & 0.962 & $0.929,0.996$ & $0.029^{*}$ & 0.963 & $0.932,0.995$ & $0.023^{*}$ \\
\hline Screen time $\geq 3 \mathrm{~h} / \mathrm{d}$ & 2.535 & $1 \cdot 069,6 \cdot 014$ & $0.035^{\star}$ & $2 \cdot 887$ & $1 \cdot 335,6 \cdot 152$ & $0.006^{*}$ \\
\hline Fish ( $\geq 4$ times/week) & 0.058 & $0.005,0.675$ & $0.023^{*}$ & $0 \cdot 138$ & $0.018,1.077$ & 0.059 \\
\hline
\end{tabular}

Only statistically significant parameters are presented in the table. *Statistically significant difference $(P \leq 0.05)$.

coming from twin and adoption studies ${ }^{(12)}$. When using BMI to quantify adiposity, the twin literature gives fairly consistent estimates of the proportion of within-population variation in adiposity that is attributable to within-population genetic variation, with heritability estimates exceeding $70 \%{ }^{(13)}$. However, the contribution to BMI from shared environmental factors has been less certain. A recently published longitudinal twin study from Finland found that the effect of common environment on BMI variation disappeared in adolescence probably as a result of the increasing independence that leads to a more individualistic eating and exercise behaviour ${ }^{(14)}$. The common environment also influences food preferences in young children; however, this effect also declines in young adulthood when food preferences are determined mainly by additive genetics and specific environmental factors ${ }^{(15)}$. In our study we included families having children aged 11 and 12 years, just before adolescence when children become more independent in making their own choices, in whom there was considerable influence of familial environmental factors on the formation of childhood obesity.

It is now widely accepted that obesity is generally inversely correlated to the indicators of socio-economic status in developed countries ${ }^{(16)}$, whereas the reverse is true for developing countries ${ }^{(17)}$. This pattern was not clearly visible in the paediatric population in the past ${ }^{(18)}$; however it has become more apparent in the last 15 years ${ }^{(19)}$. In our study, the XXI family was characterized by a lower educational status of both parents, whereas the mother's tertiary education seemed to act as a protective factor against a family becoming overweight. On the contrary, annual family income and area of residence were not significantly associated with the XXL family. Shrewsbury and Wardle ${ }^{(19)}$ recently reviewed all cross-sectional studies investigating childhood adiposity and socio-economic status that have been published since 1990 and showed that, when the socio-economic indicators were examined individually, parental education was more consistently inversely associated with adiposity, followed by parental occupation and family income. Correspondingly, a study from Greece has shown a significant inverse association between parental education and BMI in a cohort of children aged 6-17 years ${ }^{(20)}$, whereas Moschonis et al. ${ }^{(21)}$ showed that children whose mothers had a college degree were 0.56 times less likely to be overweight compared with those whose mothers had only lower secondary education or less. Although in some studies differences in child feeding and physical activity have been identified, a greater understanding of how parental education influences dietary intake and lifestyle is needed in order to establish effective preventive interventions.

Our study showed that children in obese families spend $>3 \mathrm{~h} / \mathrm{d}$ in front of a screen, a greater proportion compared with normal families. Watching television is considered as a significant contributor to childhood obesity among preschool and school-aged children and adolescents and this phenomenon is mediated mainly through increased energy intake and overconsumption of highly advertised junk food $^{(22)}$ and to a lesser extent through reduced physical activity $^{(23)}$. In addition, increased television watching has been associated with unhealthy dietary patterns such as lower intakes of vegetables, grains and dairy food ${ }^{(24)}$ and increased consumption of high-fat and high-sugar foods ${ }^{(22)}$ and soft drinks ${ }^{(25)}$. In our study, a child spending $>3 \mathrm{~h}$ in front of a screen almost triples the odds for predicting an XXL family in the multivariate analysis. The other significant parameter in the multivariate analysis was the reduced meal duration. Indeed, reduction of meal duration by 5 min increased the odds of predicting an XXL family by approximately 30\%. Rapid eating has not been widely studied as a potential contributor to the development of childhood obesity. Recently, Berkowitz et al. ${ }^{(26)}$ investigated the association of children's eating behaviour and parental feeding prompts with excess weight gain in children born at high or low risk of obesity that was determined by maternal BMI. Results showed that child mouthfuls of total energy intake per minute from food predicted an increased risk of overweight or obesity at the age of 6 years, whereas greater active mealtime was associated with a reduced risk of being overweight or obese. More elegantly designed studies have questioned the underlying pathophysiological mechanisms and have shown a higher postprandial response of the anorexigenic hormones peptide $\mathrm{YY}$ and glucagon-like peptide-1 after a 30-min meal than after a 5-min meal ${ }^{(27)}$.

In previous studies a consistent association between skipping meals and increased rates of childhood obesity has been documented ${ }^{(28)}$. In the present study, we have shown a significantly increased prevalence of children having three meals or fewer per day in XXL families compared with normal families. Although breakfast consumption is associated with a reduced risk of overweight or obesity and a reduced BMI in children and adolescents 
in Europe, it is also the commonly skipped meal ${ }^{(29)}$. Meal skipping can either have a causative role in obesity or develop as an unhealthy practice of a false dietetic plan.

With regard to weekly consumption of various food groups and the availability of various food products and beverages at home, no significant differences were recorded between XXL families and others. However, these results may have been influenced by methodological limitations such as the subjective nature of collecting data from a questionnaire completed by parents. Thus, this lack of significant 'unhealthy' dietary habits in the XXL family could be attributed either to a reverse causative phenomenon or to preventive steps that members of XXL families have been taking towards changing dietary habits. However, when the XXL families were compared with families in which all members had normal BMI, a number of significant deviations were observed.

Parental obesity not only interacts with childhood obesity in a causative manner but also sabotages the likely success of multidisciplinary childhood obesity programmes $^{(30)}$. Thus, weight management programmes for treating childhood obesity should be family oriented and should combine dietary, behavioural and physical activity interventions. Future steps to prevent childhood obesity should focus on identifying behavioural risk factors within the family that predispose children to excessive weight gain. Limiting children's and consequently the whole family's television-viewing time and discouraging a rapid eating style, laying emphasis on spending quality time as a family during meals, are two behaviours that conflict with the profile of the XXL family, apart from higher parental educational level, as indicated by the results of our study.

\section{Acknowledgements}

No funding was obtained for this study and there is no conflict of interest. A.C. conceived the study, interpreted the results, conducted the statistical analysis and wrote the manuscript; S.B. participated in the collection of the data and helped to draft the manuscript; H.P. participated in the design of the study; M.P. participated in the collection of the data; D.C. participated in the design and coordination of the study. The authors would like to thank the children and their parents for their willing participation in the study.

\section{References}

1. Wang $Y$ \& Lobstein T (2006) Worldwide trends in childhood overweight and obesity. Int J Pediatr Obes 1, 11-25.

2. Lissau I, Overpeck MD, Ruan WJ et al. (2004) Body mass index and overweight in adolescents in 13 European countries, Israel, and the United States. Arch Pediatr Adolesc Med 158, 27-33.

3. Tambalis KD, Panagiotakos DB, Kavouras SA et al. (2010) Eleven-year prevalence trends of obesity in Greek children: first evidence that prevalence of obesity is leveling off. Obesity (Silver Spring) 18, 161-166.
4. Weiss R, Dziura J, Burgert TS et al. (2004) Obesity and the metabolic syndrome in children and adolescents. $N$ Engl J Med 350, 2362-2374.

5. Whitaker RC, Wright JA, Pepe MS et al. (1997) Predicting obesity in young adulthood from childhood and parental obesity. N Engl J Med 337, 869-873.

6. Berenson GS \& Srnivasan SR (2005) Cardiovascular risk factors in youth with implications for aging: the Bogalusa Heart Study. Neurobiol Aging 26, 303-307.

7. Strauss RS \& Knight J (1999) Influence of the home environment on the development of obesity in children. Pediatrics 103, e85.

8. Perusse L, Rankinen T, Zuberi A et al. (2005) The human obesity gene map: the 2004 update. Obes Res 13, $381-490$.

9. Marti A \& Martinez JA (2006) Genetics of obesity: gene $x$ nutrient interactions. Int J Vitam Nutr Res 76, 184-193.

10. Cole TJ, Bellizzi MC, Flegal KM et al. (2000) Establishing a standard definition for child overweight and obesity worldwide: international survey. BMJ 320, 1240-1243.

11. World Health Organization (1998) Obesity: Preventing and Managing the Global Epidemic. Report of a WHO Consultation on Obesity. Geneva: WHO.

12. Silventoinen K, Rokholm B, Kaprio J et al. (2010) The genetic and environmental influences on childhood obesity: a systematic review of twin and adoption studies. Int J Obes (Lond) 34, 29-40.

13. Maes HH, Neale MC \& Eaves LJ (1997) Genetic and environmental factors in relative body weight and human adiposity. Behav Genet 27, 325-351.

14. Lajunen HR, Kaprio J, Keski-Rahkonen A et al. (2009) Genetic and environmental effects on body mass index during adolescence: a prospective study among Finnish twins. Int J Obes (Lond) 33, 559-567.

15. Breen FM, Plomin R \& Wardle J (2006) Heritability of food preferences in young children. Physiol Behav 88, 443-447.

16. Parsons TJ, Power C, Logan S et al. (1999) Childhood predictors of adult obesity: a systematic review. Int J Obes Relat Metab Disord 23, Suppl. 8, S1-S107.

17. Wang Y (2001) Cross-national comparison of childhood obesity: the epidemic and the relationship between obesity and socioeconomic status. Int J Epidemiol 30, 1129-1136.

18. Sobal J \& Stunkard AJ (1989) Socioeconomic status and obesity: a review of the literature. Psychol Bull 105, 260-275.

19. Shrewsbury V \& Wardle J (2008) Socioeconomic status and adiposity in childhood: a systematic review of crosssectional studies 1990-2005. Obesity (Silver Spring) 16, 275-284.

20. Krassas GE, Tzotzas T, Tsametis C et al. (2001) Determinants of body mass index in Greek children and adolescents. J Pediatr Endocrinol Metab 14, Suppl. 5, S1327-S1333.

21. Moschonis G, Grammatikaki E \& Manios Y (2008) Perinatal predictors of overweight at infancy and preschool childhood: the GENESIS study. Int J Obes (Lond) 32, 39-47.

22. Manios Y, Kondaki K, Kourlaba G et al. (2009) Television viewing and food habits in toddlers and preschoolers in Greece: the GENESIS study. Eur J Pediatr 168, 801-808.

23. Robinson TN (2001) Television viewing and childhood obesity. Pediatr Clin North Am 48, 1017-1025.

24. Feldman S, Eisenberg ME, Neumark-Sztainer D et al. (2007) Associations between watching TV during family meals and dietary intake among adolescents. J Nutr Educ Behav 39, 257-263.

25. Coon KA, Goldberg J, Rogers BL et al. (2001) Relationships between use of television during meals and children's food consumption patterns. Pediatrics 107, e7.

26. Berkowitz RI, Moore RH, Faith MS et al. (2010) Identification of an obese eating style in 4-year-old children born at high and low risk for obesity. Obesity (Silver Spring) 18, 505-512. 
27. Kokkinos A, le Roux CW, Alexiadou K et al. (2010) Eating slowly increases the postprandial response of the anorexigenic gut hormones, peptide YY and glucagon-like peptide-1. J Clin Endocrinol Metab 95, 333-337.

28. Koletzko B \& Toschke AM (2010) Meal patterns and frequencies: do they affect body weight in children and adolescents? Crit Rev Food Sci Nutr 50, 100-105.
29. Szajewska H \& Ruszczynski M (2010) Systematic review demonstrating that breakfast consumption influences body weight outcomes in children and adolescents in Europe. Crit Rev Food Sci Nutr 50, 113-119.

30. Eliakim A, Kaven G, Berger I et al. (2002) The effect of a combined intervention on body mass index and fitness in obese children and adolescents - a clinical experience. Eur J Pediatr 161, 449-454. 